sion sports (ice hockey, US football, the baseball catcher). The face mask may consist of metal wire, coated wire, or a transparent polycarbonate shield.

When protective eyewear has been employed in racket sports and face protection devices employed in hockey, eye injuries have been eliminated ${ }^{10,13}$.

\section{Routine examination}

Practitioners providing medical screening for athletes should have facilities for vision testing and basic eye examination at their disposal and be aware of both the basic principles of eye protection in sports and the available eyewear. It is recommended that athletes have their vision tested and eyes examined on a regular basis. Vision or eye problems are best corrected by an eye care specialist when detected early. An examination also offers an opportunity to discuss any sports vision needs and the most appropropriate type of protective eyewear.

\section{References}

1. Portis, J.M., S.A. Vassallo and D.M. Albert. Ocular sports injuries: a review of cases on file in the Massachusetts Eye and Ear Infirmary Pathology Laboratory International Ophthalmology Clinics 1981 21, 4,I

2. Vinger, P.F. The incidence of eye injuries in sports International Ophthalmology Clinics 1981, 21, 4, 21

3. Burke, M.J., Sanitato, J.J. Vinger, P.F., Raymond, L.A. and Kulwin, D.R. Soccerball induced injuries. Journal of the American Medical Association 1983, 249, 2682

\section{Blood doping}

\section{A statement from the Medical Commission of the International Olympic Committee}

Initial rumours on potential use of blood withdrawal and reinfusion with the aim of improving performance in endurance events arose after the 1976 Olympic Games in Montreal. Since then, this method and possible ways of detection have been subject to serious concern by the IOC Medical Commission.

The practice was banned for the 1988 Olympic Games in Calgary and Seoul although a reliable method for detection does not yet exist.

The IOC has partially financed recent research performed by specialists in Sweden who have endeavoured to
4. Pashby, T.J. Eye injuries in hockey International Ophthalmology Clinics 1981, 21, 4, 59

5. Vinger, P.F. and Tolpin, D.W.Racket sports: an ocular hazard Journal of the American Medical Association 1978, 239, 2575

6. American Society of Testing and Materials. Consumer safety specification for eye and face protective equipment for hockey players (F513-86). Philadelphia, Pennsylvania, 1986

7. American Society of Testing and Materials. Eye protection for use by players of racket sports (F80388). Philadelphia, Pennsylvania, 1988

8. Canadian Standard Association: National standard of Canada (CAN 3-Z262.2-M78). Face protectors for ice hockey and box lacrosse players. Rexdale, Ontario, 1978

9. Canadian Standards Association: National standard of Canada (P400-M 1982). Racket sports eye protection preliminary standard. Toronto, Ontario, 1982

10. Pashby, T.J. Eye injuries in Canadian hockey: phase III. Older players now at risk Canadian Medical Association Journal 1979, 121, 663

11. Giovinazzo, V.J., Yannuzzi, L.A., Sorenson, De Browe, J.A. and D.L. Campbell, E.A. The ocular complications of boxing Ophthalmology 1987, 94, 587

12. Smith, D.J. Ocular injuries in boxers. Proceedings of the Research to prevent Blindness, Inc., Science Writers Seminar 1987, 17-18

13. Easterbrook, M. Eye protection in racket sports: an update The Physician and Sportsmedicine 1987, 15, 180

find a way to prove that the blood haemoglobin content of an athlete has been manipulated. The first results showed that 50 per cent of blooddoped athletes could be detected if a minimum of two blood samples could be analysed before and after competition. This is certainly a step forward in the right direction, but the reliability and the validity of this test are still too low for its application during Olympic Games, where doping control should never result in false positive or false negative results.

Other methods based on the simple determination of haemoglobin concentration in the blood of participating athletes would certainly disqualify innocent individuals having high values due to genetic influences, living or training at high altitude, etc.

For the moment, careful examination of the medical equipment of teams entering a country and inspection of potential injection marks on the
Suggested reading

Davis J.K. Lenses for sports vision. In: Pizzarello, L.D. and Haik, B.G. (Eds.): Sports Ophthalmology. Springfield, Illinois, Charles C. Thomas, 1987.

Vinger, P.F. The eye and sports medicine. In: Duane, T.D. (Ed.): Clinical Ophthalmology. Philadelphia, Harper \&

Row, 1985.

This position statement was prepared by Paul F. Vinger, M.D. (Lexington, MA, USA) and Howard G. Knuttgen, Ph.D. (Boston, MA, USA) in collaboration with Michael Easterbrook, M.D. (Toronto, Ont, Canada) and Thomas J. Pashby, M.D. (Don Mills, Ont, Canada).

\section{Appendix}

Eye and face protector standards

Racket Sports (Sports frame and sports eyeguards

ATSM Z803-86 Eye protection for use by players of racket sports

CSA P400-M 1982 Racket sports eye protection, preliminary standard

Hockey

ASTM F513-86 Eye and face protective equipment for hockey players

CSA CAN 3-Z262.2-M78 Face protectors for ice hockey and box lacrosse players

Baseball

ASTM F910 Qualifications for Skiing

faceguards for youth baseball

ASTM F659 Specifications for eye protective devices for alpine skiing ASTM American Society of Testing and Materials

CSA Canadian Standard Association

athlete's body seem to be the only possible ways of preventing blood doping. No blood products were reported by Canadian customs before the XVth Olympic Winter Games in Calgary and no evidence of recent blood transfusion has been detected by members of the IOC Medical Commission when inspecting the athletes undergoing the normal procedure of medical control after competition.

Unconfirmed reports regarding the possible use of the newly developed hormone erythropoetin (EPO) to increase the number of red cells and the haemoglobin concentration in the blood of athletes should be qualified as pure speculation at the present time. EPO is available at this stage from only a limited number of sources for clinical investigational studies in severely anaemic patients in order to avoid the necessity of blood transfusions.

Calgary, 27th February 1988 